\title{
Polymorphism of SYNE2 Gene and its Association with Litter Size in Small Tail Han Sheep
}

\author{
Zhilong Tian ${ }^{1,2}$, Yuqin Wang ${ }^{2}$, Jishun Tang ${ }^{1,3}$ and Mingxing $\mathrm{Chu}^{1 *}$ \\ ${ }^{1}$ Key Laboratory of Animal Genetics and Breeding and Reproduction of Ministry \\ of Agriculture and Rural Affairs, Institute of Animal Science, Chinese Academy of \\ Agricultural Sciences, Beijing 100193, China \\ ${ }^{2}$ College of Animal Science and Technology, Henan University of Science and \\ Technology, Luoyang, Henan 471003, China \\ ${ }^{3}$ Institute of Animal Husbandry and Veterinary Medicine, Anhui Academy of \\ Agricultural Sciences, Hefei 230031, China
}

\begin{abstract}
A B S T R A C T
To elucidate the association between polymorphism of SYNE2 and litter size in sheep and provide a new locus for marker-assisted selection of high fecundity traits in sheep. A total of 384 small tail han sheep (STH) were sampled to detect single nucleotide polymorphism (SNP), and Sequenom Mass ARRAY ${ }^{\circledR}$ SNP assay was applied to genotype SNP loci of the SYNE2 gene. In this study, four SNPs were identified and that SNPs were identified that involved in amino acid changes. Population genetic analysis indicated that SYNE2 gene g.73310578G $>$ A, g. $73312791 \mathrm{~A}>\mathrm{G}$ showed moderate polymorphism $(0.25<\mathrm{PIC}<0.5)$ in Small Tail Han sheep. Furthermore, g.73310578G $>$ A and g.73312791A $>$ G loci were closely linked in STH $\left(r^{2}>0.33\right)$. Association analysis results showed that g.73310578G $>$ A and g.73312791A $>$ G SNPs significantly affected litter size $(P<0.05)$. In addition, the litter size of individuals with the combined genotype AA/AG was greater than that of individuals with $\mathrm{AA} / \mathrm{GG}, \mathrm{GA} / \mathrm{AG}$, and $\mathrm{GG} / \mathrm{AA}$ genotypes in the third parity $(P<0.05)$. In summary, the SYNE2 gene had a positive influence on the litter size of STH sheep. The linkage of g.73310578G $>$ A and g.73312791 $\mathrm{A}>\mathrm{G}$ could be used in the marker-assisted selection of the litter size of STH.
\end{abstract}

Article Information
Received 15 August 2019
Revised 22 September 2019
Accepted 01 October 2019
Available online 12 February 2021
Authors' Contribution
YW, ZT and MC designed the study.
JT and ZT conducted the experiments.
ZT analyzed the data and drafted
the manuscript. YW, ZT, JS and
MC helped in preparation of the
manuscript.
Key words
Sheep, SYNE2 gene, SNP, Genotyping,
Litter size

Received 15 August 2010

Revised 22 September 2019

Accepted 01 October 2019

Authors' Contribution

JT and ZT conducted the experiments.

$\mathrm{ZT}$ analyzed the data and drafted

the manuscript. YW, ZT, JS and

MC helped in preparation of the

Key word

Litter size

\section{INTRODUCTION}

$\mathrm{L}$ itter size plays a vital role in the livestock economy (Rothschild et al., 1996). The litter size in sheep is a complex trait that is influenced by many factors, such as genetic background (Chu et al., 2007), nutritional level (Mellor, 1983), and feeding management. The genetic experience principally includes the number of ovulation (Chu et al., 2007), fertilization efficiency (Edwards et al., 2016), and estrus (Sánchez-Dávila et al., 2015). Among them, the ovulation is particularly important, which can affect the number of lambs per year in the sheep. Identification of the candidate genes that are responsible for variation in continuous traits or quantitative traits has been a challenge in modern genetics. So far, there have been some studies of a candidate gene, such as $F e c B$, $B M P 15$, and GDF9 on reproductive traits in sheep, which

\footnotetext{
* Corresponding author: mxchu@263.net 0030-9923/2021/0002-0537 \$ 9.00/0

Copyright 2021 Zoological Society of Pakistan
}

revealed that candidate gene plays an important role in sheep reproduction. The $F e c B$ gene is crucial in the regulation of prolificacy phenotype in sheep (Mulsant et al., 2001).

Nuclear envelope spectrin repeat proteins (Nesprins) are the latest identified members of the spectrin repeat (SR)-containing protein family (Zhou et al., 2018a). Nesprin-1/2 giant isoforms localize at the outer nuclear membrane and form the L Inker of Nucleoskeleton-andCytoskeleton (LINC) complex via associations between their KASH domains and the SUN domains of SUN1/2 in the perinuclear space (Sosa et al., 2012; Sosa et al., 2013). The LINC complex tethers the nuclear envelope to cytoskeletal elements, including actin filaments and the microtubule network (Gimpel et al., 2017; Wilson and Holzbaur, 2015). This molecular linking network is pivotal in regulating nuclear integrity, maintaining nuclear-cytoskeleton coupling, and participating in mechanotransduction, nuclear migration and positioning uniquely in muscle cell differentiation (Mellad et al., 2011; Stroud et al., 2014; Zhou et al., 2018a). Previous studies 
have suggested that Nesprin-2 regulates the Wnt $/ \beta$-catenin signaling pathway (Sascha et al., 2010; Zhang et al., 2016). Several reports have shown that the $\mathrm{Wnt} / \beta$-catenin pathway plays an essential role in follicular development, granulosa cell growth, and oocyte maturation (Gustin et al., 2016). Most studies on the SYNE2 gene have focused on diseases in the human (Baumann et al., 2017; Marina et al., 2015) and the mouse (Zhou et al., 2018a). However, few studies have investigated the effect of the SYNE2 gene on litter size in sheep. Therefore, the objectives of the present research were to detect SNPs associated with the litter size in small tail han (STH) sheep and identify a genetic marker conceivably valuable for marker-assisted selection.

\section{MATERIALS AND METHODS}

All the experimental procedures mentioned in the present study were approved by the Science Research Department (in charge of animal welfare issue) of the Institute of Animal Sciences, Chinese Academy of Agricultural Sciences (IAS-CAAS) (Beijing, China). Ethical approval on animal survival was given by the animal ethics committee of IAS-CAAS (No. IASCAASAE-03, 12 December 2016).

Animals selection, blood sampling, and DNA extraction

As detailed in Table I, 726 ewes from six sheep breeds were selected for genotyping. Jugular vein blood samples ( $10 \mathrm{~mL}$ blood per ewe) were collected using citrate glucose as an anticoagulant. Genomic DNA was extracted by the phenol-chloroform method (Deininger, 1983), dissolved in $\mathrm{ddH}_{2} \mathrm{O}$ and stored at $-20^{\circ} \mathrm{C}$.

\section{Primer design and genotyping}

Four pairs of primers were designed according to the ovine SYNE2 sequence from Ensemble (ENSOART00000023042.1). Primer sequence, product size and annealing temperature are presented in Table II. All primers were synthesized by Beijing Tianyihuiyuan Biotechnology Co. Ltd. (Beijing, P.R. China). PCR was carried out in $50 \mu \mathrm{L}$ volume containing $25 \mu \mathrm{L}$ of $2 \times \mathrm{GC}$ Buffer I , $8 \mu \mathrm{L}$ of $2.5 \mathrm{mmol} / \mathrm{L}$ each dNTP, $0.5 \mu \mathrm{L}$ of $5 \mathrm{U} / \mu \mathrm{L}$ TaKaRa LA Taq, $2 \mu \mathrm{L}$ of $40 \mathrm{ng} / \mu \mathrm{L}$ genomic DNA, and $1 \mu \mathrm{L}$ of $10 \mu \mathrm{mol} / \mathrm{L}$ each primer, the rest was $\mathrm{ddH}_{2} \mathrm{O}$. Amplification conditions were as follows: initial denaturation at $95^{\circ} \mathrm{C}$ for $5 \mathrm{~min}$; followed by 34 cycles of denaturation at $95^{\circ} \mathrm{C}$ for $30 \mathrm{~s}$, annealing for $30 \mathrm{~s}$, extension at $72^{\circ} \mathrm{C}$ for $1 \mathrm{~min}$ with a final extension at $72^{\circ} \mathrm{C}$ for $5 \mathrm{~min}$.

All of the PCR products were sent to Sangon Biotech Co, Ltd. (Shanghai, China). The sequencer software Chromas Pro 2 was used to identify SNPs. Genotyping of SYNE2 SNPs by Sequenom MassARRAY ${ }^{\circledR}$ SNP as described by Zhou (Zhou et al., 2018b). Genotyping primer sequence and product size are presented in Table II.

\section{Statistical analysis}

Allelic frequencies, heterozygosity $(\mathrm{He})$, polymorphism information content (PIC) and the HardyWeinberg equilibrium tests were calculated using Pop gene (version 1.31). Linkage disequilibrium was analyzed using Haploview. Statistical analysis was performed by univariate analysis in a General Linear Model procedure of SAS (V. 8.1) (SAS Institute Inc., Cary, NC, USA). Multiple comparisons of means were performed using the least significant difference method. The applied model was expressed as follows: $\mathrm{y}_{\mathrm{ijn}}=\mu+P_{i}+G_{j}+I_{P G}+\mathrm{e}_{\mathrm{ijn}}$, where $\mathrm{y}_{\mathrm{ijn}}$ is the phenotypic value of litter size; $\mu$ is the population mean; $P_{i}$ is the fixed effect of the $i$ th parity $(\mathrm{i}=1,2,3)$; $G_{j}$ is the fixed effect of the $j$ th genotype $(\mathrm{j}=1,2,3) ; I_{P G}$ is the interaction effect of parity and genotype; and $\mathrm{e}_{\mathrm{ijn}}$ is the random residual.

\section{RESULTS}

Polymorphisms of the coding region of the SYNE2 gene

In this study, sequencing of the amplicons of different primer pairs identified four polymorphic nucleotide sites in sheep SYNE2 gene. The g.73310578G $>$ A mutation was in the 112 exons and the g.73312892G $>$ A, g.73312791A $>\mathrm{G}$ and g.73314606G $>$ A mutations were in the 114 exons (Fig. 1). Four SNPs (g.73310578G $>$ A, g.73312892G $>$ A, g.73312791 $\mathrm{A}>\mathrm{G}$ and g.73314606G $>\mathrm{A}$ ) were genotyped in STH sheep (Fig. 2). At g.73312892G $>$ A locus, the PIC was 0.07 in STH (Fig. 2). At g. $73310578 \mathrm{G}>$ A, g. $73314606 \mathrm{G}>\mathrm{A}$ and g. $73312791 \mathrm{~A}>\mathrm{G}$ locus, the PIC was $0.18 \sim 0.30$ in STH. Genotypic distribution and allelic frequencies of four SNPs are shown in Figure 2. It was shown that STH sheep were in Hardy-Weinberg equilibrium at four-locus ( $p>$ 0.05 ) (Fig. 2). To reveal the linkage relationships between the four SNPs, the linkage disequilibrium was estimated at in STH sheep (Fig. 3). If $\mathrm{r}^{2}>0.33$ and D' $>0.5$ the linkage disequilibrium was considered strong (Ardlie et al., 2002). Following the result, both g.73310578G $>$ A and g.73312791 A $>$ G loci were closely linked in STH sheep.

Population genetic analysis of polymorphism in the SYNE2 gene

Besides STH sheep (Fig. 2), population genetic characteristics of four SNPs in the other five sheep breeds were also analyzed, the results were listed in Table III. It revealed that the g.73314606G $>A$ and g.73312791A $>$ G loci were moderately polymorphic $(0.25<\mathrm{PIC}<0.5)$ in the Sunite sheep and $\mathrm{Hu}$ sheep, respectively. 
Table I. Information of six sheep breeds selected for genotyping.

\begin{tabular}{lll}
\hline Breed & Number & District \\
\hline Small tail han sheep & 384 & Yuncheng, Shandong Province, China \\
Hu sheep & 101 & Xuzhou, Jiangsu Province, China \\
Cele black sheep & 68 & Cele, Hetian, Xinjiang Uigur Autonomous Region, China \\
Prairie Tibetan sheep & 80 & Dangxiong, Tibet Autonomous Region, China \\
Sunite sheep & 70 & Wulatezhongqi, Bayannaoer, Inner Mongolia Autonomous Region, China \\
Tan sheep & 23 & Yanchi, Ningxia Hui Autonomous Region, China \\
\hline
\end{tabular}

Table II. Information of primer in sheep SYNE2 gene.

\begin{tabular}{|c|c|c|c|c|}
\hline Primer name & Primer sequence & $\mathbf{T m}$ & product size & Amplified region \\
\hline SYNE2-1 & $\begin{array}{l}\text { F: CATCACTGTTTTCAGAGTGCCT } \\
\text { R: ATACCTCTTCTCCCACCCACG }\end{array}$ & 59.5 & $342 \mathrm{bp}$ & Exon112 \\
\hline SYNE2-2 & $\begin{array}{l}\text { F: TTCCTGTCTAGATGATGCCAG } \\
\text { R: GCTGCAAGGACACTAAGTCT }\end{array}$ & 58.9 & $352 \mathrm{bp}$ & Exon114 \\
\hline SYNE2-3 & $\begin{array}{l}\text { F: AAGCTGATTCCGGCCACAC } \\
\text { R: CAGGGCCATAACGTAGCTTT }\end{array}$ & 60.6 & $341 \mathrm{bp}$ & Exon114 \\
\hline SYNE2-4 & $\begin{array}{l}\text { F: CATGCTGGCTCTAGTCCCCT } \\
\text { R: TAGAAGGACCTGGCAAAGTTGT }\end{array}$ & 61.1 & $332 \mathrm{bp}$ & Exon114 \\
\hline SYNE2-1-S & $\begin{array}{l}\text { F:ACGTTGGATGAGCTGGCTGACTCTATCTTG } \\
\text { R:ACGTTGGATGTCTCTGTCAACGTGAACAGC }\end{array}$ & 60.0 & $102 \mathrm{bp}$ & PCR for $\mathrm{g} .73310578 \mathrm{G}>\mathrm{A}$ \\
\hline SYNE2-1-E & 5'- TGACTCTATCTTGGAGTTCT -3' & & & Extension reaction \\
\hline SYNE2-2-S & $\begin{array}{l}\text { F: ACGTTGGATGCCTAGCAACTGGAAAAGGAG } \\
\text { R: ACGTTGGATGTAAGCAGGGTGCTGGAAATC }\end{array}$ & & $98 \mathrm{bp}$ & PCR for g. $73312791 \mathrm{~A}>\mathrm{G}$ \\
\hline SYNE2-2-E & 5'- AAAGGAGCTAGTGGAAC -3' & & & Extension reaction \\
\hline SYNE2-3-S & $\begin{array}{l}\text { F: ACGTTGGATGGGAGAAGACTACATTGAGGC } \\
\text { R: ACGTTGGATGGGGACACTTGCTCAAGTAAC }\end{array}$ & & 99 bp & PCR for $\mathrm{g} .73312892 \mathrm{G}>\mathrm{A}$ \\
\hline SYNE2-3-E & 5'- aggaTGAAGAGAAGGTCCATGTTATC -3' & & & Extension reaction \\
\hline SYNE2-4-S & $\begin{array}{l}\text { F: ACGTTGGATGAGCTCTCACCTCCTCTGTTG } \\
\text { R: ACGTTGGATGTGATCACCCGAGAAAGGAAG }\end{array}$ & & $109 \mathrm{bp}$ & PCR for g.73314606G $>$ A \\
\hline SYNE2-4-E & 5'- tgaCCGATCCCGCTGCCCCC $-3{ }^{\prime}$ & & & Extension reaction \\
\hline
\end{tabular}
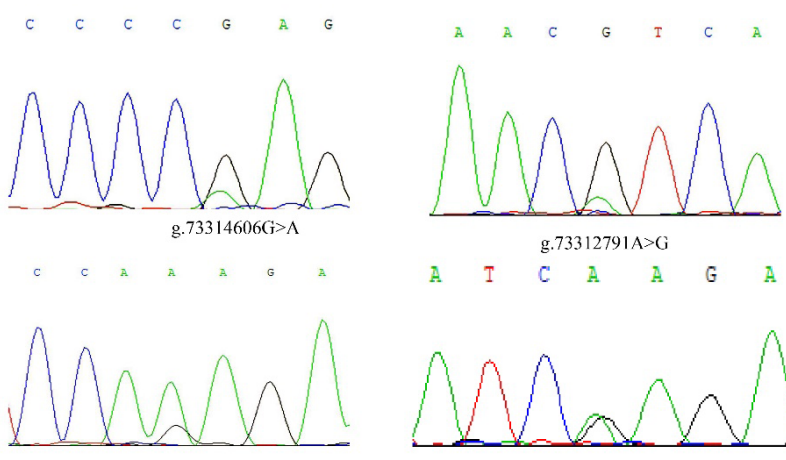

g. $73310578 G>A$

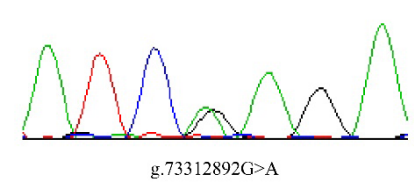

Fig. 1. Identification SNP of SYNE2 gene in small tail han sheep.
The chi-square test indicated that all SNPs under Hardy Weinberg equilibrium $(P>0.05)$ in six sheep breeds. Besides, we classified six breeds into two categories, Multiparous and uniparous, based on the litter size characteristics, the results of the comparison of the population genetic analysis were shown in Table IV.

Association analysis of SNPs with litter size

At the g.73312892G $>$ A locus in the STH sheep, individuals with the GG genotype higher litter size than did those with AA genotypes in each parity (Table V). However, it did not reach a significant level $(P>0.05)$. At other loci, no significant differences in each parity litter size between different genotypes were found. The results of association analysis of the combined genotypes showed 
Table III. Population genetic analysis of four loci of SYNE2 in five sheep breeds.

\begin{tabular}{|c|c|c|c|c|c|c|c|c|c|c|}
\hline \multirow{2}{*}{$\begin{array}{l}\text { Locus } \\
\text { g.73312892G>A }\end{array}$} & \multirow[t]{2}{*}{ Breed } & \multicolumn{3}{|c|}{ Genotype frequency } & \multicolumn{2}{|c|}{ Allele frequency } & \multirow[t]{2}{*}{ PIC } & \multirow[t]{2}{*}{ HE } & \multirow[t]{2}{*}{ NE } & \multirow[t]{2}{*}{ Chi-Square test (P-value) } \\
\hline & & GG & AG & AA & $\mathrm{G}$ & A & & & & \\
\hline & Hu sheep & 0.90 & 0.09 & 0.01 & 0.95 & 0.05 & 0.10 & 0.10 & 1.11 & 0.18 \\
\hline & Prairie Tibetan sheep & 0.84 & 0.16 & 0.00 & 0.92 & 0.08 & 0.13 & 0.14 & 1.17 & 0.29 \\
\hline & Cele black sheep & 0.98 & 0.02 & 0.00 & 0.99 & 0.01 & 0.02 & 0.02 & 1.02 & 0.94 \\
\hline & Sunite sheep & 0.81 & 0.19 & 0.00 & 0.90 & 0.10 & 0.16 & 0.17 & 1.21 & 0.63 \\
\hline & Tan sheep & 0.86 & 0.14 & 0.00 & 0.93 & 0.07 & 0.12 & 0.13 & 1.15 & 0.73 \\
\hline \multirow[t]{6}{*}{ g. $73310578 \mathrm{G}>\mathrm{A}$} & & $\mathrm{AA}$ & GA & GG & A & G & & & & \\
\hline & Hu sheep & 0.69 & 0.29 & 0.02 & 0.84 & 0.16 & 0.24 & 0.27 & 1.38 & 0.61 \\
\hline & Prairie Tibetan sheep & 0.77 & 0.20 & 0.03 & 0.87 & 0.13 & 0.20 & 0.23 & 1.29 & 0.12 \\
\hline & Cele black sheep & 0.73 & 0.23 & 0.04 & 0.85 & 0.15 & 0.23 & 0.26 & 1.35 & 0.41 \\
\hline & Sunite sheep & 0.67 & 0.33 & 0.00 & 0.83 & 0.17 & 0.24 & 0.28 & 1.38 & 0.36 \\
\hline & Tan sheep & 0.82 & 0.18 & 0.00 & 0.91 & 0.09 & 0.15 & 0.17 & 1.20 & 0.64 \\
\hline \multirow[t]{6}{*}{ g. $73314606 \mathrm{G}>\mathrm{A}$} & & AA & GA & GG & A & $\mathrm{G}$ & & & & \\
\hline & Hu sheep & 0.04 & 0.28 & 0.68 & 0.18 & 0.82 & 0.25 & 0.29 & 1.41 & 0.59 \\
\hline & Prairie Tibetan sheep & 0.04 & 0.22 & 0.74 & 0.15 & 0.85 & 0.22 & 0.25 & 1.34 & 0.13 \\
\hline & Cele black sheep & 0.02 & 0.12 & 0.86 & 0.08 & 0.92 & 0.14 & 0.15 & 1.17 & 0.06 \\
\hline & Sunite sheep & 0.00 & 0.38 & 0.62 & 0.19 & 0.81 & 0.26 & 0.31 & 1.45 & 0.28 \\
\hline & Tan sheep & 0.00 & 0.27 & 0.73 & 0.14 & 0.86 & 0.21 & 0.24 & 1.31 & 0.46 \\
\hline \multirow[t]{6}{*}{ g. $73312791 \mathrm{~A}>\mathrm{G}$} & & AA & GA & GG & A & G & & & & \\
\hline & Hu sheep & 0.02 & 0.38 & 0.60 & 0.21 & 0.79 & 0.28 & 0.33 & 1.49 & 0.15 \\
\hline & Prairie Tibetan sheep & 0.03 & 0.20 & 0.77 & 0.13 & 0.87 & 0.20 & 0.23 & 1.29 & 0.12 \\
\hline & Cele black sheep & 0.04 & 0.23 & 0.73 & 0.15 & 0.85 & 0.23 & 0.26 & 1.35 & 0.41 \\
\hline & Sunite sheep & 0.00 & 0.29 & 0.71 & 0.14 & 0.86 & 0.21 & 0.24 & 1.32 & 0.44 \\
\hline & Tan sheep & 0.00 & 0.18 & 0.82 & 0.09 & 0.91 & 0.15 & 0.17 & 1.20 & 0.64 \\
\hline
\end{tabular}

Note: PIC, HE and NE represent polymorphism information content, heterozygosity and effective number of alleles, respectively; $p>0.05$ indicates the locus was under Hardy-Weinberg equilibrium.

Table IV. Genotype and allele frequencies of four loci in SYNE2 gene of sheep with different litter size characteristics.

\begin{tabular}{|c|c|c|c|c|c|c|c|}
\hline \multirow[t]{2}{*}{ Loci } & \multirow[t]{2}{*}{ Characteristics of litter size } & \multicolumn{3}{|c|}{ Genotype frequency } & \multicolumn{2}{|c|}{ Allele frequency } & \multirow[t]{2}{*}{ Chi-square test (P-value) } \\
\hline & & GG & $\mathrm{AG}$ & $\mathrm{AA}$ & G & $\mathrm{A}$ & \\
\hline \multirow[t]{3}{*}{ g. $73312892 \mathrm{G}>\mathrm{A}$} & Polytocous sheep & 0.92 & 0.08 & - & 0.96 & 0.04 & 0.00 \\
\hline & Monotocous sheep & 0.84 & 0.16 & - & 0.92 & 0.08 & \\
\hline & & AA & GA & GG & A & $\mathrm{G}$ & \\
\hline \multirow[t]{3}{*}{ g.73310578G $>A$} & Polytocous sheep & 0.62 & 0.32 & 0.06 & 0.78 & 0.22 & 0.00 \\
\hline & Monotocous sheep & 0.76 & 0.21 & 0.03 & 0.87 & 0.13 & \\
\hline & & AA & GA & GG & A & G & \\
\hline \multirow[t]{3}{*}{ g. $73314606 \mathrm{G}>\mathrm{A}$} & Polytocous sheep & 0.02 & 0.21 & 0.77 & 0.12 & 0.88 & 0.34 \\
\hline & Monotocous sheep & 0.02 & 0.25 & 0.73 & 0.15 & 0.85 & \\
\hline & & $\mathrm{AA}$ & GA & GG & A & $\mathrm{G}$ & \\
\hline \multirow[t]{2}{*}{ g. $73312791 \mathrm{~A}>\mathrm{G}$} & Polytocous sheep & 0.06 & 0.35 & 0.21 & 0.23 & 0.77 & 0.00 \\
\hline & Monotocous sheep & 0.02 & 0.21 & 0.77 & 0.13 & 0.87 & \\
\hline
\end{tabular}


Table V. Analysis of different loci and litter size at SYNE2 gene in small tail han sheep.

\begin{tabular}{lllll}
\hline Loci & Genotype & $\mathbf{1}^{\text {st }}$ parity litter size & $\mathbf{2}^{\text {nd }}$ parity litter size & $\mathbf{3}^{\text {rd }}$ parity litter size \\
\hline g.73312892G $>$ A & AG & $1.77 \pm 0.16(30)$ & $1.96 \pm 0.18(28)$ & $2.00 \pm 0.35(13)$ \\
g.73310578G $>$ A & GG & $2.05 \pm 0.05(312)$ & $2.24 \pm 0.06(299)$ & $2.39 \pm 0.10(147)$ \\
& AA & $2.01 \pm 0.06(197)$ & $2.20 \pm 0.07(188)$ & $2.33 \pm 0.13(93)$ \\
& GG & $2.17 \pm 0.16(30)$ & $2.21 \pm 0.18(28)$ & $2.34 \pm 0.36(12)$ \\
g.73312791A $>$ G & GA & $2.08 \pm 0.08(120)$ & $2.23 \pm 0.09(115)$ & $2.32 \pm 0.17(55)$ \\
& AA & $2.08 \pm 0.17(26)$ & $2.13 \pm 0.20(24)$ & $2.19 \pm 0.38(11)$ \\
g.73314606G $>$ A & AG & $2.07 \pm 0.08(125)$ & $2.27 \pm 0.09(120)$ & $2.31 \pm 0.16(59)$ \\
& GG & $2.02 \pm 0.07(180)$ & $2.22 \pm 0.07(171)$ & $2.46 \pm 0.14(84)$ \\
& AA & $2.23 \pm 0.21(3)$ & $2.37 \pm 0.16(3)$ & $2.40 \pm 0.21(2)$ \\
& AG & $2.10 \pm 0.11(66)$ & $2.27 \pm 0.12(66)$ & $2.29 \pm 0.23(31)$ \\
\hline
\end{tabular}

Note: Numbers in the parentheses next to litter size represent the amount of sheep of each genotype.

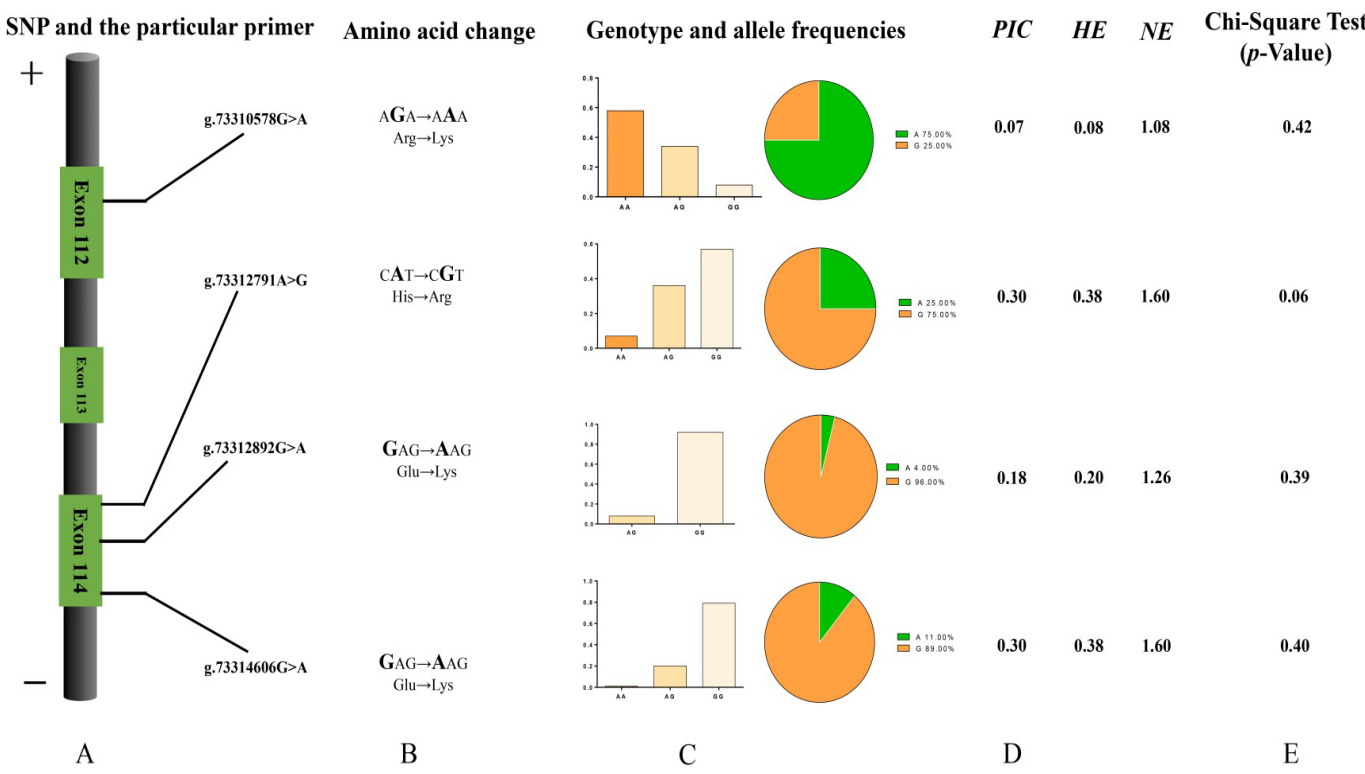

Fig. 2. Polymorphisms of the SYNE2 gene in small tail han Sheep. A, the detected SNP and particular primer. A total of 4 exons are included in the SYNE2 gene of sheep; B, the change of amino acids; C, the genotype and allele frequencies of the $S Y N E 2$ gene; $\mathrm{D}$, the information of PIC, HE and NE; E, the test of HWE, $P>0.05$ indicates the locus was in Hardy-Weinberg equilibrium.

Table VI. Association analysis of $S Y N E 2$ haplotype and litter size in small tail han Sheep.

\begin{tabular}{lllll}
\hline Genotype & Number & $\begin{array}{l}\mathbf{1}^{\text {st }} \text { parity } \\
\text { litter size }\end{array}$ & $\begin{array}{l}\mathbf{2}^{\text {nd }} \text { parity } \\
\text { litter size }\end{array}$ & $\begin{array}{l}\mathbf{3}^{\text {rd }} \text { parity } \\
\text { litter size }\end{array}$ \\
\hline AAAG & 8 & $2.00 \pm 0.30$ & $2.63 \pm 0.32 \mathrm{~b}$ & $2.75 \pm 0.32 \mathrm{~b}$ \\
AAGG & 176 & $2.08 \pm 0.06$ & $2.21 \pm 0.07 \mathrm{a}$ & $2.25 \pm 0.07 \mathrm{a}$ \\
GAAG & 113 & $2.11 \pm 0.08$ & $2.15 \pm 0.09 \mathrm{a}$ & $2.19 \pm 0.09 \mathrm{a}$ \\
GGAA & 25 & $2.06 \pm 0.17$ & $2.12 \pm 0.18 \mathrm{a}$ & $2.15 \pm 0.18 \mathrm{a}$ \\
\hline
\end{tabular}

Note: Different small letters in the same group mean a significant difference $(p<0.05)$. that individuals in the STH sheep with the AA/AG genotype had larger litter sizes than did those with AA/ GG, GA/AG and GG/AA genotypes in the second and third parity $(P<0.05$; Table VI).

\section{DISCUSSION}

Several reports have shown that nesprins (nuclear envelope spectrin repeat proteins) are the latest identified members of the spectrin repeat (SR)-containing protein family (Zhang et al., 2001). To date, six genes encoding 
for different KASH domain-containing proteins named as nesprins-1, -2, -3, -4, lymphoid-restricted membrane protein (LRMP) and KASH5 have been identified in mammals (Zhou et al., 2018a). Nesprins play pivotal roles in the maintenance of NE integrity (Luke et al., 2008), nuclear positioning (Zhang et al., 2007) and anchorage to the cytoskeleton and the centrosome (Roux et al., 2009). Previous studies have suggested that Nesprin-2 regulates the Wnt/ $\beta$-catenin signaling pathway (Sascha et al., 2010; Zhang et al., 2016). Several reports have shown that the $\mathrm{Wnt} / \beta$-catenin pathway plays an important role in follicular development, granulosa cell growth and oocyte maturation (Gustin et al., 2016). WNT families consist of local-acting glycoproteins. They can regulate a wide range of biological processes, which include cell fate determination, proliferation, differentiation, apoptosis and embryogenesis (Fan et al., 2010). Therefore, we want to know that the $S Y N E 2$ gene is related to sheep reproduction or not and then detect SNPs of the SYNE2 gene in STH sheep and identify a genetic marker conceivably valuable for marker-assisted selection (MAS).

\begin{tabular}{|l|l|l|}
\hline \multicolumn{3}{|c|}{ Last Selection: (chr7:73310578, chr7:73312791) - D': 0.951 LOD: 100.84 r-squared: 0.891} \\
\hline
\end{tabular}

Fig. 3. The g.73310578G $>A$ and g.73312791A $>\mathrm{G}$ loci linkage disequilibrium.

In this study, a total of four SNPs were identified and that SNPs were identified as that involved in amino acid change all SNPs were in Hardy-Weinberg disequilibrium in six sheep $(P>0.05)$. Previous studies have demonstrated that $\mathrm{Ne}$ and $\mathrm{PIC}$ are important genetic parameters that indicate the level of intra-population genetic variation (Botstein et al., 1980). The results of the present study show that the g.73314606G $>$ A and g.73312791A $>$ G loci were moderately polymorphic $(0.25<\mathrm{PIC}<0.5)$ in the Sunite sheep and $\mathrm{Hu}$ sheep, respectively. These results indicated that the g.73314606G $>A$ and g.73312791A $>$ G loci have a higher level of intra-population genetic variation. The results of this study show that we found g.73312892G $>$ A, g.73310578G $>$ A, g.73312791A $>$ G, g.73314606G $>$ A are all missense mutations. There are many studies that missense mutations change sheep reproductive traits, such as FecB, BMP15, and GDF9 (Chong et al., 2018; Zhou et al., 2018b). Several studies indicated that ewes carrying FecB-mutation have significantly higher ovulation rates if compared with their wild-type contemporaries (Mulsant et al., 2001; Qiuyue et al., 2015). Six mutations $\left(F e c X^{I}, F e c X^{H}, F e c X^{G}, F e c X^{B}, F e c X^{L}, F e c X^{R}\right)$ of bone morphogenetic protein 15 (BMP15) can increase ovulation rate in heterozygotes and cause complete sterility in homozygotes. However, homozygous ewes with mutations $\left(F e c X^{G r}, F e c X^{O}\right)$ of BMP15 had increased ovulation rate without causing sterility (Qiuyue et al., 2015). Five mutations $\left(F e c G^{H}, \quad F e c G^{T}, F e c G^{E}, F e c G^{F}, F e c G^{V}\right)$ in growth differentiation factor $9(G D F 9)$ associated with sheep prolificacy where $\mathrm{FecG}^{\mathrm{E}}$ and $\mathrm{FecG}^{\mathrm{F}}$ have additive an effect on ovulation rate and litter size (Qiuyue et al., 2015). When amino acid changes, the spatial structure of the protein changes, but its function may not change. The association analysis has shown that the four SNPs have no significant differences in each parity litter size between different genotypes. Further research is required to verify the mechanism of the impact of the SNPs on the parity litter size in STH sheep. Reproductive traits are complex quantitative traits involving multiple genes, loci and their interactions. Therefore, the combined effects of multiple genes or loci on reproductive traits should be analyzed. Association analysis revealed that mutations at g.73310578G $>\mathrm{A}$ and g.73312791A $>\mathrm{G}$ had a significant impact on litter size in STH sheep, which is consistent with the linkage disequilibrium result. The interesting finding was that of association analysis of the combined genotypes showed that individuals in the STH sheep with the AA/AG genotype had larger litter sizes than did those with $\mathrm{AA} / \mathrm{GG}$, GA/AG and GG/AA genotypes in the second and third parity. This result may be explained by the fact that this mutation in linkage disequilibrium with other responsible mutations or this mutation may change some events of SYNE2 in term of the post-transcriptional regulation (Oerum et al., 2017; Zhang et al., 2019).

\section{CONCLUSIONS}

In Summary, the current study explored the genetic polymorphisms in the coding region of the SYNE2 gene, indicating that the AAAG haplotypes of SYNE2 gene g.73310578G $>$ A and g.73312791A $>$ G linkage loci could influence the third parity litter size in STH sheep. Therefore, it could be useful in the marker-assisted selection of the second and third parity litter size in STH sheep.

\section{ACKNOWLEDGMENTS}

This research was funded by the National Natural 
Science Foundation of China (31772580), Earmarked Fund for China Agriculture Research System (CARS38), Central Public-interest Scientific Institution Basal Research Fund (Y2017JC24), Agricultural Science and Technology Innovation Program of China (ASTIP-IAS13), China Agricultural Scientific Research Outstanding Talents and Their Innovative Teams Program, China High-level Talents Special Support Plan Scientific and Technological Innovation Leading Talents Program (W02020274), and Tianjin Agricultural Science and Technology Achievements Transformation and Popularization Program (201704020).

Statement of conflict of interest

All authors declare no conflicts of interest

\section{REFERENCES}

Ardlie, K.G., Kruglyak, L. and Seielstad, M., 2002. Patterns of linkage disequilibrium in the human genome. Nature Rev. Genet., 3: 299-309. https:// doi.org/10.1038/nrg777

Baumann, M., Steichen-Gersdorf, E., Krabichler, B., Petersen, B.S., Weber, U., Schmidt, W.M., Zschocke, J., Muller, T., Bittner, R.E. and Janecke, A.R., 2017. Homozygous SYNE1 mutation causes congenital onset of muscular weakness with distal arthrogryposis: a genotype-phenotype correlation. Eur. J. Hum. Genet., 25: 262-266. https://doi. org/10.1038/ejhg.2016.144

Botstein, D., White, R.L., Skolnick, M. and Davis, R.W.J.A.J.o.H.G., 1980. Construction of a genetic linkage map in man using restriction fragment length polymorphisms. Am. J. Hum. Genet., 32: 314-331.

Chong, Y., Huang, H., Liu, G., Jiang, X. and Rong, W., 2018. A single nucleotide polymorphism in the zona pellucida 3 gene is associated with the first parity litter size in $\mathrm{Hu}$ sheep. Anim. Reprod. Sci., 193: 26-32. https://doi.org/10.1016/j. anireprosci.2018.03.028

Chu, M.X., Liu, Z.H., Jiao, C.L., He, Y.Q., Fang, L., Ye, S.C., Chen, G.H. and Wang, J.Y., 2007. Mutations in $B M P R-I B$ and $B M P-15$ genes are associated with litter size in Small Tailed Han sheep (Ovis aries). J. Anim. Sci., 85: 598-603. https://doi.org/10.2527/ jas.2006-324

Deininger, P., 1983. Molecular cloning: A laboratory manual. $2^{\text {nd }}$ ed. Cold Spring Harbor Laboratory Press, NY, pp. 182-183.

Edwards, S.J., Smaill, B., O’Connell, A.R., Johnstone, P.D., Stevens, D.R., Quirke, L.D., Farquhar, P.A. and Juengel, J.L., 2016. Reduced ovulation rate, failure to be mated and fertilization failure/embryo loss are the underlying causes of poor reproductive performance in juvenile ewes. Anim. Reprod. Sci., 167: 125-132. https://doi.org/10.1016/j. anireprosci.2016.02.017

Fan, H.Y., O’Connor, A., Shitanaka, M., Shimada, M., Liu, Z. and Richards, J.S. 2010. Beta-catenin (CTNNB1) promotes preovulatory follicular development but represses LH-mediated ovulation and luteinization. Mol. Endocrinol., 24: 1529-1542. https://doi.org/10.1210/me.2010-0141

Gimpel, P., Lee, Y.L., Sobota, R.M., Calvi, A., Koullourou, V., Patel, R., Mamchaoui, K., Nedelec, F., Shackleton, S. and Schmoranzer, J., 2017. Nesprin-1alpha-dependent microtubule nucleation from the nuclear envelope via akap450 is necessary for nuclear positioning in muscle cells. Curr. Biol., 27: 2999-3009. https://doi.org/10.1016/j. cub.2017.08.031

Gustin, S.E., Hogg, K., Stringer, J.M., Rastetter, R.H., Pelosi, E., Miles, D.C., Sinclair, A.H., Wilhelm, D. and Western, P.S., 2016. WNT/ $\beta$-catenin and p27/FOXL2 differentially regulate supporting cell proliferation in the developing ovary. Develop. Biol., 412: 250-260. https://doi.org/10.1016/j. ydbio.2016.02.024

Luke, Y., Zaim, H., Karakesisoglou, I., Jaeger, V.M., Sellin, L., Lu, W., Schneider, M., Neumann, S., Beijer, A., Munck, M., Padmakumar, V.C., Gloy, J., Walz, G. and Noegel, A.A., 2008. Nesprin-2 giant (NUANCE) maintains nuclear envelope architecture and composition in skin. J. Cell Sci., 121: $1887-$ 1898. https://doi.org/10.1242/jcs.019075

Marina, F., Marco, S., Nascimbeni, A.C., Giuseppina, D.F., Ebe, P., Elisabetta, T., Trevisan, C.P., Vincenzo, N. and Corrado, A., 2015. Dominant muscular dystrophy with a novel SYNE1 gene mutation. Muscle Nerve, 51: 145-147. https://doi. org/10.1002/mus.24357

Mellad, J.A., Warren, D.T. and Shanahan, C.M., 2011. Nesprins LINC the nucleus and cytoskeleton. Curr. Opin. Cell Biol., 23: 47-54. https://doi. org/10.1016/j.ceb.2010.11.006

Mellor, D.J., 1983. Nutritional and placental determinants of foetal growth rate in sheep and consequences for the newborn lamb. Br. Vet. J., 139: 307-324. https://doi.org/10.1016/S00071935(17)30436-0

Mulsant, P., Lecerf, F., Fabre, S., Schibler, L., Monget, P., Lanneluc, I., Pisselet, C., Riquet, J., Monniaux, D. and Callebaut, I., 2001. Mutation in bone morphogenetic protein receptor-IB is associated 
with increased ovulation rate in Booroola Merino ewes. Proc. natl. Acad. Sci., 98: 5104-5109. https:// doi.org/10.1073/pnas.091577598

Oerum, S., Roovers, M., Leichsenring, M., AcquavivaBourdain, C., Beermann, F., Gemperle-Britschgi, C., Fouilhoux, A., Korwitz-Reichelt, A., Bailey, H.J. and Droogmans, L., 2017. Novel patient missense mutations in the $H S D 17 B 10$ gene affect dehydrogenase and mitochondrial tRNAmodification functions of the encoded protein. Biochim. biophys. Acta (BBA)-Mol. Basis Dis., 1863: 3294-3302. https://doi.org/10.1016/j.bbadis.2017.09.002

Qiuyue, L., Zhangyuan, P., Xiangyu, W., Wenping, H., Ran, D., Yaxing, Y. and Mingxing, C., 2015. Progress on major genes for high fecundity in ewes. Front. Agric. Sci. Engineer., 1: 282-290. https://doi. org/10.15302/J-FASE-2014042

Rothschild, M., Jacobson, C., Vaske, D., Tuggle, C., Wang, L., Short, T., Eckardt, G., Sasaki, S., Vincent, A. and Mclaren, D., 1996. The estrogen receptor locus is associated with a major gene influencing litter size in pigs. Proc. natl. Acad. Sci. USA,93: 201205. https://doi.org/10.1073/pnas.93.1.201

Roux, K.J., Crisp, M.L., Liu, Q., Kim, D., Kozlov, S., Stewart, C.L. and Burke, B., 2009. Nesprin 4 is an outer nuclear membrane protein that can induce kinesin-mediated cell polarization. Proc. natl. Acad. Sci. USA, 106: 2194-2199. https://doi.org/10.1073/ pnas. 0808602106

Sánchez-Dávila, F., Bernal-Barragán, H., Padilla-Rivas, G., Bosque-González, A.S.D., Vázquez-Armijo, J.F. and Ledezma-Torres, R.A., 2015. Environmental factors and ram influence litter size, birth, and weaning weight in Saint Croix hair sheep under semi-arid conditions in Mexico. Trop. Anim. Hlth. Produc. Anim., 47: 825-831. https://doi.org/10.1007/ s11250-015-0795-6

Sascha, N., Maria, S., Daugherty, R.L., Gottardi, C.J., Eming, S.A., Asa, B., Noegel, A.A. and Iakowos, K., 2010. Nesprin-2 interacts with \{alpha\}-catenin and regulates Wnt signaling at the nuclear envelope. J. biol. Chem., 285: 34932-34938. https://doi. org/10.1074/jbc.M110.119651

Sosa, B., Rothballer, A., Kutay, U. and Schwartz, T., 2012. LINC complexes form by binding of three KASH peptides to domain interfaces of trimeric SUN proteins. Cell, 149: 1035-1047. https://doi. org/10.1016/j.cell.2012.03.046

Sosa, B.A., Ulrike, K. and Schwartz, T.U., 2013. Structural insights into LINC complexes. Curr. Opin. Struct. Biol., 23: 285-291. https://doi.org/10.1016/j. sbi.2013.03.005

Stroud, M.J., Banerjee, I., Veevers, J. and Chen, J., 2014. Linker of nucleoskeleton and cytoskeleton complex proteins in cardiac structure, function, and disease. Circul. Res., 114: 538-548. https://doi.org/10.1161/ CIRCRESAHA.114.301236

Wilson, M.H. and Holzbaur, E.L., 2015. Nesprins anchor kinesin-1 motors to the nucleus to drive nuclear distribution in muscle cells. Development, 142: 218228. https://doi.org/10.1242/dev.114769

Zhang, Q., Minaisah, R.M., Ferraro, E., Li, C., Porter, L.J., Zhou, C., Gao, F., Zhang, J., Rajgor, D. and Autore, F., 2016. N-terminal nesprin-2 variants regulate $\beta$-catenin signalling. Exp. Cell Res., 345: 168-179. https://doi.org/10.1016/j.yexcr.2016.06.008

Zhang, Q., Skepper, J.N., Yang, F., Davies, J.D., Hegyi, L., Roberts, R.G., Weissberg, P.L., Ellis, J.A. and Shanahan, C.M., 2001. Nesprins: a novel family of spectrin-repeat-containing proteins that localize to the nuclear membrane in multiple tissues. J. Cell Sci., 114: 4485-4498.

Zhang, X., Xu, R., Zhu, B., Yang, X., Ding, X., Duan, S., Xu, T., Zhuang, Y. and Han, M., 2007. Syne-1 and Syne-2 play crucial roles in myonuclear anchorage and motor neuron innervation. Development, 134: 901-908. https://doi.org/10.1242/dev.02783

Zhang, Y., Cui, W., Yang, H., Wang, M., Yan, H., Zhu, H., Liu, J., Qu, L., Lan, X. and Pan, C., 2019. A novel missense mutation (L280V) within POU1F1 gene strongly affects litter size and growth traits in goat. Theriogenology, 135: 198-203. https://doi. org/10.1016/j.theriogenology.2019.06.021

Zhou, C., Rao, L., Warren, D.T., Shanahan, C.M. and Zhang, Q., 2018a. Mouse models of nesprin-related diseases. Biochem. Soc. Trans., 46: 669-681. https:// doi.org/10.1042/BST20180085

Zhou, M., Pan, Z., Cao, X., Guo, X., He, X., Sun, Q., Di, R., Hu, W., Wang, X., Zhang, X., Zhang, J., Zhang, C., Liu, Q. and Chu, M., 2018b. Single nucleotide polymorphisms in the hira gene affect litter size in small tail han sheep. Animals, 8: 71. https://doi. org/10.3390/ani8050071 